\title{
IgG-class anti-PF4/heparin antibodies and symptomatic DVT in orthopedic surgery patients receiving different anti-thromboembolic prophylaxis therapeutics
}

Satoru Motokawa', Takafumi Torigoshi ${ }^{1}$, Yumi Maeda ${ }^{2}$ Kazushige Maeda' ${ }^{1}$, Yuka Jiuchi ${ }^{2}$, Takayuki Yamaguchi ${ }^{1}$, Shinsuke Someya ${ }^{1}$, Hiroyuki Shindo ${ }^{3}$, Kiyoshi Migita2*

\begin{abstract}
Background: Heparin-induced thrombocytopenia (HIT) is a thromboembolic complication that can occur with unfractionated heparin (UFH) or low molecular weight heparin (LMWH). Our objective was to determine and compare the incidence of IgG-class HIT antibodies in patients undergoing total hip arthroplasty (THA) or total knee arthroplasty (TKA) with different antithrombotic prophylaxis therapies and their contributions to the occurrence of venous thromboembolism (VTE).
\end{abstract}

Methods: A prospective observational study was performed for 374 Japanese patients undergoing THA or TKA to determine the incidence of VTE. IgG-class anti-PF4/heparin antibodies were measured using IgG-specific EIA before and after the operation.

Results: In the clinical outcome, the incidence of symptomatic deep vein thrombosis (DVT) was 15.0\% (56/374, TKA; 35, THA; 21) and pulmonary emboli (PE) were not observed. The total seroconversion incidence of IgG-class PF4/heparin antibodies was 19.8\% (74/374). The seroconversion incidence of IgG-class PF4/heparin antibodies was higher in patients receiving UFH (32.7\%) compared to those receiving LMWH (9.5\%) or fondaparinux (14.8\%). Furthermore, the seroconversion incidence was significantly higher in patients undergoing TKA compared to those undergoing THA. Based on multivariate analysis, seroconversion of the IgG-class PF4/heparin antibodies was independent a risk factor for symptomatic DVT.

Conclusion: Our findings show that the seroconversion of IgG-class anti-PF4/heparin antibodies differed with various anti-thrombotic prophylaxis therapeutics and was associated with the risk of DVT in a subset of patients undergoing total joint arthroplasty (TKA and THA).

\section{Background}

Venous thromboembolism (VTE) is a serious complication of major orthopedic surgery including total hip arthroplasty (THA) and total knee arthroplasty (TKA) [1]. The incidence of postoperative deep vein thrombosis (DVT) is $45-57 \%$ after THA and $41-85 \%$ after TKA if prophylaxis is not used [2]. Consequently, pharmacological thromboprophylaxis is recommended and widely

\footnotetext{
* Correspondence: migita@nmc.hosp.go.jp

${ }^{2}$ Clinical Research Center, NHO Nagasaki Medical Center, Kubara 2-1001-1,

Omura 856-8652, Japan

Full list of author information is available at the end of the article
}

used in patients undergoing orthopedic surgery [3]. Although, low-dose unfractionated heparin (UFH) has been used as a thromboprophylactic agent, enoxaparin and fondaparinux have recently been approved for thromboprophylaxis in patients after TKA or THA in Japan $[4,5]$. LMWHs is an important tool in DVT management, offering advantages over UFH, considering the reduced risk for HIT [6], a prothrombotic adverse drug reaction caused by platelet-activating antibodies that recognize the complex of platelet factor 4 (PF4) bound to heparin [7]. Indeed, HIT is found in approximately $5 \%$ of patients receiving unfractionated heparin

\section{Biomed Central}


thromboprophylaxis in orthopedic surgery studies [8]. By contrast, a reduced risk of HIT has been confirmed in patients receiving LMWH or fondaparinux [9]. HIT is caused by the generation of heparin-dependent antibodies against the PF4/heparin complex, which cause platelet activation and aggregation and eventually progress to thrombocytopenia and thrombosis [10]. Recent studies have confirmed a minor role of IgM- and IgAclass anti-PF4/heparin antibodies in HIT $[11,12]$ and there is growing evidence that only antibodies of the IgG class are capable of inducing platelet activation [13]. The aim of the present study was to determine the risk factors of VTE, and the incidence of symptomatic DVTs and PEs in patients undergoing THA or TKA under pharmacologic prophylaxis. Furthermore, in this study, we used a specific immunoassay that detects only IgGclass anti-PF4/heparin antibodies to determine the frequency of these antibodies and their contributions to the occurrence of VTEs.

\section{Methods}

\section{Patients}

All patients who underwent THA or TKA at our institution between September 1 2006, and April 30 2010, were enrolled in this study to determine the incidence of PE and symptomatic DVT. Data were collected regarding baseline patient characteristics, including age, gender, underlying disease and VTE risk factors (previous thrombosis, malignancy, diabetes, hypertension, hyperlipidemia and arrhythmia). Bleeding was defined as overt if it was clinically evident and there was a clear source of bleeding. None of the patients had any history of previous heparin exposure within the past 90 days. The study protocol was approved by the Ethics Committees of the Nagasaki Medical Center and written informed consent was obtained from each patient.

\section{Thromboprophylaxis Regimen}

Our institution has used unfractionated heparin (UFH) since 2004. Patients received 1000 units of UFH via a single bolus intravenous injection during the operation and 5000 units of UFH via drip intravenous infusion $(24 \mathrm{hr})$ on post-operative day 2 . Since June 2007, fondaparinux and enoxaparin have been approved for post-operative thromboprophylaxis in Japan. Four months later, we changed the thromboprophylactic regimen to fondaparinux or enoxaparin in our institute. Fondaparinux $(2.5 \mathrm{mg}$ once a day) or enoxaparin (2,000 IU twice a day) were injected subcutaneously for 10 days. The operation was performed under general anesthesia in all cases. In TKA, air tourniquent was used during operation in all cases. All TKAs were performed with a cemented component. THAs were almost performed with a cementless femoral stem and an acetabular component. A foot pump (A-V
Impulse System, Novamedix Corp, Hampshire, UK) and compression stockings were initiated on day 1 in all subjects.

\section{Detection of DVT/PE}

After the operation, primary screening for VTE was undertaken by meticulous observation of the clinical signs, and determination of plasma D-dimer levels. For the clinical signs of DVT-PE, we carefully examined the patient for swelling of the entire leg or localized leg swelling, acute cardiovascular dysfunction, dyspnea and chest pain. Patients who exhibited high plasma concentrations of D-dimer $>10 \mu \mathrm{g} / \mathrm{ml}$, or were suspected to exhibit the clinical signs of DVT were subjected to CT scanning using MDCT from the chest to the ankle and venous Doppler ultrasonography for detection of DVT/PE.

\section{Blood sampling}

Serum samples were collected before the operation and at postoperative day 7 , and stored at $-70^{\circ} \mathrm{C}$. A sandwich ELISA kit (GTI Diagnostics, Waukesha, WI) was used to measure the IgG-class anti-heparin-PE4 antibody (HIT Ab) titer of the serum according to the manufacturer's instructions. The microtiter wells were precoated with polyvinylsulfonate-PF4 complexes. Antibodies bound to polyvinylsulfonate-PF4 were identified by affinity-purified anti-human IgG peroxidase conjugate. ELISA reactivities (optical density, OD) are expressed relative to a standard control. Positive and negative controls were included in every plate. The samples with readings $\geq 0.40$ absorbance units were considered positive according to the manufacturer's instructions. While the results of the ELISA test merely confirmed the presence of HIT antibodies, HIT was defined as a $>50 \%$ reduction in the platelet count or an absolute platelet count $<10^{5} / \mu$ d during and after heparin treatment, with no other cause of thrombocytopenia, and a positive result in the HIT antibody test [14].

\section{Assessment of bleeding}

During this study, the patients were examined daily for any evidence of wound hematoma, as well as other manifestations of bleeding. Bleeding was considered to be major if there was a wound hematoma necessitating surgical revision, gastrointestinal bleeding, or any bleeding requiring transfusion of more than $400 \mathrm{ml}$ of blood and interruption of prophylaxis.

\section{Statistical Analysis}

Crude associations for categorical variables were evaluated using a Chi-squared test. For continuous variables, differences between groups were evaluated by Mann-Whitney $U$ test. Multivariate analysis was conducted by fitting logistic regression analysis models to adjust for the effects of 
confounding factors while identifying significant predictors of DVT. The variables on multiple logistic regression analysis were selected from variables showing a $p$ value $<0.1$ in univariate analyses. The exact confidence intervals and probability values are reported for the multivariate models. For all other tests, a $p$ value $<0.05$ was considered statistically significant. All statistical analysis was performed with SPSS version 13.0 (Chicago, IL, USA). Odds ratios (OR) for regression modeling and their $95 \%$ confidence intervals (CI) are reported.

\section{Result}

\section{Clinical outcome}

Occurrence of VTE

The total joint arthroplasty (TKA and THA) were performed and the distributions of the patient's mean age and gender are presented in Table 1. Two hundred and fourteen patients $(57.2 \%)$ underwent THA and 160 patients $(42.8 \%)$ underwent TKA. For pharmacological VTE prophylaxis, unfractionated heparin (UFH), low molecular-weight heparin (LMWH; enoxaparin) and fondaparinux were administered in $27.8 \%, 25.4 \%$ and $21.7 \%$ of the total patients respectively. The primary diagnosis was osteoarthritis in $89.7 \%$ and $80.6 \%$ of the patients who underwent THA and TKA, respectively. Pulmonary emboli did not occur in this study. As shown in Table 2, symptomatic DVT was observed in
Table 2 Incidence of DVT and major bleeding

\begin{tabular}{llccc}
\hline $\begin{array}{l}\text { THA/ } \\
\text { TKA }\end{array}$ & drug & $\begin{array}{c}\text { No. } \\
\text { patients }\end{array}$ & $\begin{array}{c}\text { No. DVT } \\
\text { (\%) }\end{array}$ & $\begin{array}{c}\text { No. bleeding } \\
\text { (\%) }\end{array}$ \\
\hline THA & UFH & 60 & $6(10.0)$ & $3(5.0)$ \\
& LMWH & 64 & $6(9.4)$ & $1(1.6)$ \\
& Fondaparinux & 49 & $4(8.2)$ & $3(6.1)$ \\
& Others & 41 & $5(12.2)$ & $1(2.4)$ \\
\hline TKA & UFH & 44 & $10(22.7)$ & $5(11.4)$ \\
& LMWH & 31 & $8(25.8)$ & $2(6.5)$ \\
& Fondaparinux & 32 & $4(12.5)$ & $0(0)$ \\
& Others & 53 & $13(24.5)$ & $5(9.4)$ \\
\hline
\end{tabular}

Abbreviations: DVT; deep vein thrombosis, TKA; total knee arthroplasty, THA; total hip arthroplasty, UFH; unfractionated heparin, LMWH; low-molecular weight heparin.

21 patients undergoing THA (9.8\%) and 35 patients undergoing TKA (21.9\%). All of the DVTs were the distal type.

\section{Occurrence of bleeding}

Twenty (5.3\%) of the 374 operations were associated with major bleeding (Table 2). These complications did not influence the patient's ultimate outcome. There were no gastrointestinal bleeding events.

\section{Seroconversion of IgG-class PF4/heparin antibody}

The seroconversion of IgG-class PF4/heparin antibody was confirmed in $27.5 \%(44 / 160)$ of patients undergoing

Table 1 Patients characteristics

\begin{tabular}{|c|c|c|c|c|c|}
\hline Characteristics & \multicolumn{2}{|c|}{$\begin{array}{c}\text { THA } \\
n=214\end{array}$} & \multicolumn{2}{|c|}{$\begin{array}{c}\text { TKA } \\
n=160\end{array}$} & \multirow{2}{*}{$\begin{array}{l}\boldsymbol{p} \\
<0.00001\end{array}$} \\
\hline Age & $65.6 \pm 11.7$ & $(25-90)$ & $73.9 \pm 8.9$ & $(30-89)$ & \\
\hline Age $\geqq 75$ yr & 49 & & 89 & & $<0.00001$ \\
\hline Age $<75 \mathrm{yr}$ & 165 & & 71 & & \\
\hline Gender(male/female) & $34 / 180$ & & $31 / 129$ & & 0.379 \\
\hline $\mathrm{BMI}\left(\mathrm{Kg} / \mathrm{m}^{2}\right)$ & $24.1 \pm 3.8$ & $(15.1-37.7)$ & $25.9 \pm 4.3$ & $(13.7-41.4)$ & $<0.00001$ \\
\hline $\mathrm{BM} I \geqq 30$ & 17 & & 30 & & 0.002 \\
\hline $\mathrm{BMI}<30$ & 197 & & 130 & & \\
\hline Risk factors & $102 / 214$ & $(47.7 \%)$ & $112 / 160$ & (70.0\%) & $<0.00001$ \\
\hline OA/RA & $192 / 22$ & & $129 / 31$ & & 0.013 \\
\hline Seroconvertion of IgG-class Anti-PF4/heparinAb & $30 / 214$ & $(14.0 \%)$ & $44 / 160$ & $(27.5 \%)$ & 0.001 \\
\hline \multicolumn{6}{|l|}{ Treatment } \\
\hline UFH & $60 / 214$ & $(28.0 \%)$ & $44 / 160$ & (27.5\%) & 0.909 \\
\hline LMWH & $64 / 214$ & (29.9\%) & $31 / 160$ & (19.4\%) & 0.021 \\
\hline Fondaparinux & $49 / 214$ & $(22.9 \%)$ & $32 / 160$ & (20.0\%) & 0.501 \\
\hline Others & $21 / 214$ & $(9.8 \%)$ & $29 / 160$ & (18.1\%) & 0.019 \\
\hline Aspirin & $16 / 214$ & $(7.5 \%)$ & $27 / 160$ & (16.9\%) & \\
\hline Warfarin & $4 / 214$ & $(1.9 \%)$ & $1 / 160$ & $(0.6 \%)$ & \\
\hline Cilostazol & $14 / 214$ & $(6.5 \%)$ & $23 / 160$ & (14.4\%) & \\
\hline No medication & $20 / 214$ & (9.3\%) & $24 / 160$ & (15.0\%) & 0.093 \\
\hline
\end{tabular}

Abbreviations: BMl; body mass index, TKA; total knee arthroplasty, THA; total hip arthroplasty, OA; osteoarthritis, RA; rheumatoid arthritis, UFH; unfractionated heparin, LMWH; low-molecular weight heparin. 
TKA and in $14.0 \%(30 / 214)$ of those undergoing THA (Table 3). The incidence of seroconversion of IgG-class PF4/heparin antibodies was significantly higher in patients undergoing TKA compared to those undergoing THA. The seroconversion of IgG-class PF4/heparin antibodies varied with the different thromboembolic prophylaxis therapeutics. The conversion incidence of IgG-class PF4/heparin antibodies was significantly lower in patients receiving fondaparinux compared with those receiving UFH. Interestingly, seroconversion of IgG-class $\mathrm{PF} 4 /$ heparin antibodies was demonstrated in patients who did not receive UFH, LWMH or fondaparinux.

\section{Platelet count}

We compared the platelet counts before the operation and at post-operative day 7 in the patients with or without seroconversion of IgG-class PF4/heparin antibodies. Platelet counts were elevated significantly at post-operative day 7 in the presence or absence of seroconversion of IgG-class PF4/heparin antibodies and none of these patients developed HIT (Figure 1).

\section{Risk factors for DVT}

In comparisons between patients with or without DVT, several variables were selected through univariate analysis, based upon a p-value $<0.1$ (Table 4 ), and these selected parameters were then subjected to multivariate analysis. The parameters included were; age, gender, the type of operation (TKA/THA), and postoperative (7 days) seroconversion of IgG PF4/heparin antibody. Logistic regression multivariate analysis revealed older age ( $\geqq 75 \mathrm{yr}$ ), female gender and seroconversion of the IgG anti-PF4/heparin antibody as significant independent risk factors (Table 5).

Next, we determined whether seroconversion of the IgG-class HIT antibody contributed to the occurrence

\begin{tabular}{|c|c|c|c|c|}
\hline $\begin{array}{l}\text { THA/ } \\
\text { TKA }\end{array}$ & drug & $\begin{array}{c}\text { No. } \\
\text { patients }\end{array}$ & $\begin{array}{l}\text { No. seroconversion } \\
(\%)\end{array}$ & Total(\%) \\
\hline \multirow[t]{4}{*}{ THA } & UFH & 60 & $17(28.3)$ & $30(14.0)$ \\
\hline & LMWH & 64 & $4(6.3)^{*}$ & \\
\hline & Fondaparinux & 49 & $4(8.2)^{* *}$ & \\
\hline & others & 41 & $5(12.2)$ & \\
\hline \multirow[t]{4}{*}{ TKA } & UFH & 44 & 17(38.6) & $\underset{* * * *}{44(27.5)}$ \\
\hline & LMWH & 31 & $5(16.1)^{* * *}$ & \\
\hline & Fondaparinux & 32 & $8(25.0)$ & \\
\hline & others & 53 & $14(26.4)$ & \\
\hline
\end{tabular}

Abbreviations: TKA; total knee arthroplasty, THA; total hip arthroplasty, UFH; unfractionated heparin, LMWH; low-molecular weight heparin, ${ }^{*} p=0.001$ versus UFH, ${ }^{* *} p=0.008$ versus UFH, ${ }^{* * *} p=0.035$ versus UFH, ${ }^{* * * *} p=0.001$ versus THA. of DVT in the subgroups receiving the same antithrombotic prophylaxis agent (Table 6). Seroconversion of the IgG-class HIT antibody was significantly associated with the occurrence DVT in patients receiving UFH ( $p=$ 0.001 , OR; 6.2). Meanwhile, seroconversion of the IgG-class HIT antibody was not associated with the occurrence of DVT in patients receiving LMWH or fondaparinux, as well as in patients who were not treated with these prophylaxes.

\section{Discussion}

In this report we describe our studies comparing the incidence of anti-PF4/heparin antibodies in patients receiving different thromboprophylaxis therapeutics after total joint arthroplasty (TKA and THA). Previous study has reported a significant difference in HIT between unfractionated heparin (UFH) and LMWH in postoperative orthopedic patients, suggesting that LMWH is safer than UFH in these patients $[9,15]$. Our hypothesis was that the frequencies of seroconversion of IgG-class anti-PF4/heparin would be reduced in patients receiving fondaparinux, and even in those receiving LMWHs, and we focused on the relationship between seroconversion of these antibodies and the occurrence of symptomatic DVT under different anti-thrombotic prophylaxis therapeutics. We found that seroconversion of the IgG-class anti-PF4/heparin antibody occurred in a significant number of patients and that it occurred more often in post-operative patients receiving UFH compared with those receiving fondaparinux or LMWH. Furthermore, we demonstrated that seroconversion of the IgG-class anti-PF4/heparin antibody could be an independent risk factor of symptomatic DVT in the absence of thrombocytopenia. Our data also demonstrated that older age ( $\geqq 75 \mathrm{yr})$ is an independent risk factor of symptomatic DVT. Old age has already been demonstrated to be an important risk factor for VTE [3]. Our result seems to support these previous findings.

HIT is caused by heparin-dependent IgG-class antibodies against the PF4/heparin complex. These IgG immune-complexes bind to the platelet surface, resulting in platelet activation and aggregation [16]. Immune assays for PF4/heparin antibody generally detect antibodies of all classes Igs (IgG, A, and IgM) [12]. Accordingly, these immune assays can be expected to display much lower specificity, since only antibodies of the IgG class against PF4/heparin complex can activate platelets [13]. Therefore, in this prospective study, we used an IgG-specific EIA to improve the specificity for the antiPF4/heparin antibody compared with the global assay. The diagnosis of HIT is based on clinical criteria, including thrombocytopenia, which is confirmed by in vitro demonstration of anti-PF4/heparin antibodies using functional and immunological methods [17]. 


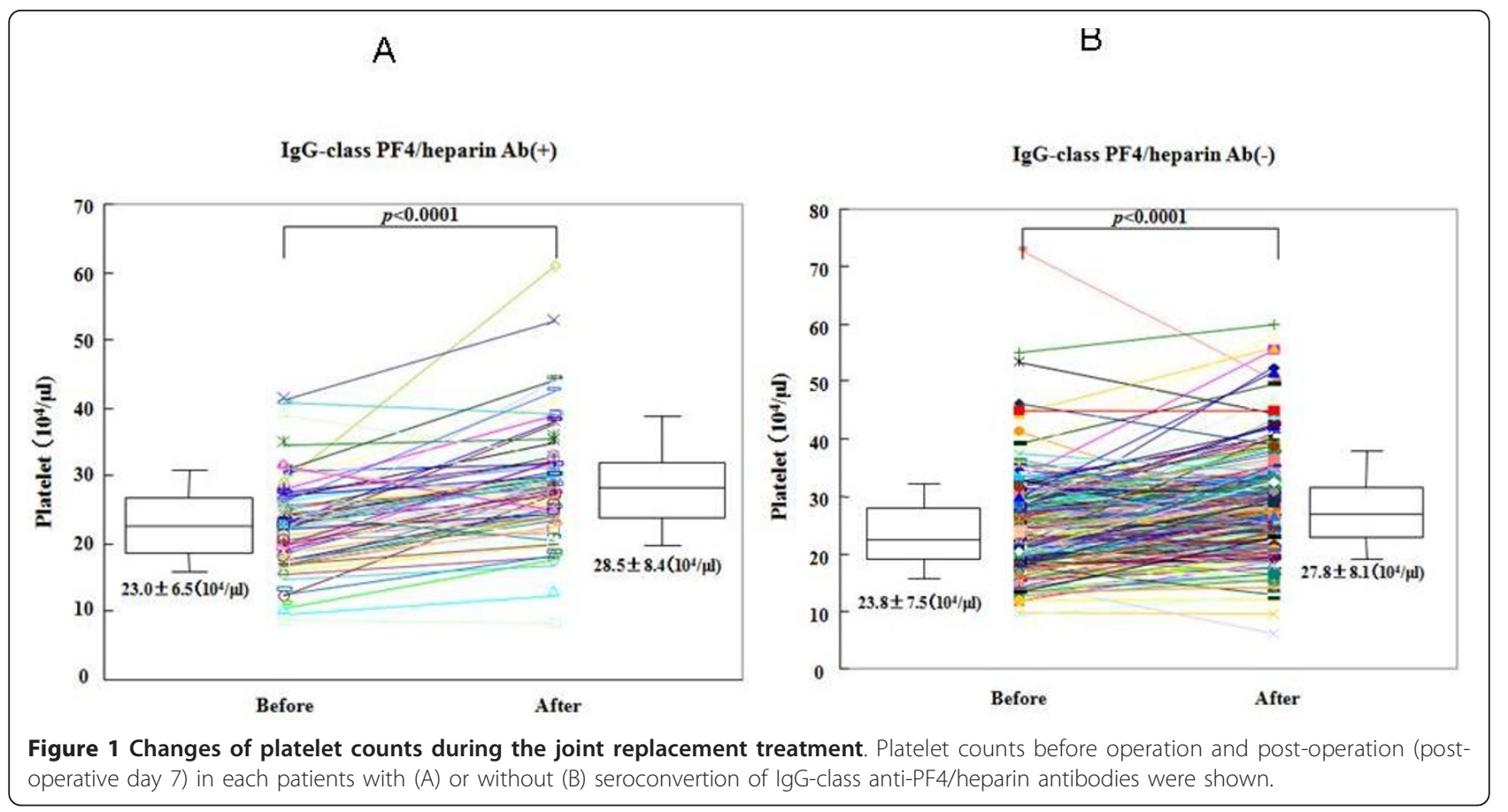

Table 4 Patients characteristics and symptomatic DVT

\begin{tabular}{|c|c|c|c|c|c|}
\hline \multirow[b]{2}{*}{ Characteristics } & \multirow{2}{*}{\multicolumn{2}{|c|}{$\begin{array}{c}\text { DVD(-) } \\
\mathrm{n}=\mathbf{3 1 8}\end{array}$}} & \multicolumn{2}{|c|}{ DVT(+) } & \multirow[b]{2}{*}{$p$} \\
\hline & & & $\mathbf{n}=$ & 56 & \\
\hline Age & $68.2 \pm 11.6$ & $(25-90)$ & $74.5 \pm 7.8$ & $(45-86)$ & $<0.00001$ \\
\hline Age $\geqq 75 \mathrm{yr}$ & 106 & & 32 & & 0.001 \\
\hline Age $<75 \mathrm{yr}$ & 212 & & 24 & & \\
\hline Gender(male/female) & $60 / 258$ & & $5 / 51$ & & 0.070 \\
\hline $\operatorname{BMI}\left(\mathrm{Kg} / \mathrm{m}^{2}\right)$ & $24.7 \pm 4.2$ & $(13.7-41.4)$ & $25.8 \pm 3.8$ & $(20.1-35.1)$ & 0.088 \\
\hline $\mathrm{BMI} \geqq 30$ & 37 & & 10 & & 0.195 \\
\hline $\mathrm{BMI}<30$ & 281 & & 46 & & \\
\hline Risk factors & $176(55.3 \%)$ & & $38(67.9 \%)$ & & 0.081 \\
\hline TKA/THA & $125 / 193$ & & $35 / 21$ & & 0.001 \\
\hline OA/RA & $273 / 46$ & & $48 / 7$ & & 0.697 \\
\hline Seroconvertion of IgG-class Anti-PF4/heparin Ab & $54(17.0 \%)$ & & $20(35.7 \%)$ & & 0.001 \\
\hline \multicolumn{6}{|l|}{ Treatment } \\
\hline UFH & 89 & $(27.7 \%)$ & 16 & $(28.6 \%)$ & 0.890 \\
\hline LMWH & 81 & $(25.5 \%)$ & 14 & $(25.0 \%)$ & 0.940 \\
\hline Fondaparinux & 73 & $(23.0 \%)$ & 8 & $(14.3 \%)$ & 0.146 \\
\hline Others & 37 & $(11.6 \%)$ & 13 & $(23.2 \%)$ & \\
\hline Aspirin & 31 & $(9.7 \%)$ & 12 & (21.4\%) & \\
\hline Warfarin & 5 & $(1.6 \%)$ & 0 & & \\
\hline Cilostazol & 26 & $(8.2 \%)$ & 11 & $(19.6 \%)$ & \\
\hline No medication & 39 & $(12.3 \%)$ & 5 & $(8.9 \%)$ & 0.475 \\
\hline
\end{tabular}

Abbreviations: DVT; deep vein thrombosis; BMI; body mass index, TKA; total knee arthroplasty, THA; total hip arthroplasty, OA; osteoarthritis, RA; rheumatoid arthritis, UFH; unfractionated heparin, LMWH; low-molecular weight heparin. 
Table 5 Multivariate analysis for risk factors of symptomatic DVT

\begin{tabular}{lccc}
\hline Variable & $\boldsymbol{p}$ & HR & 95\%Cl \\
\hline Age $\geqq 75$ yr & 0.010 & 2.396 & $(1.227-4.677)$ \\
Male Gender & 0.041 & 0.353 & $(0.130-0.957)$ \\
Risk factors & 0.760 & 1.114 & $(0.556-2.233)$ \\
TKA/THA & 0.074 & 1.792 & $(0.944-3.401)$ \\
Seroconvertion of IgG-class HIT Ab & 0.005 & 2.583 & $(1.338-4.984)$ \\
\hline
\end{tabular}

Abbreviations: DVT; deep vein thrombosis, TKA; total knee arthroplasty, THA; total hip arthroplasty, HR; Hazard Ratio, $\mathrm{Cl}$; Confidence Interval.

Although functional assays are considered to represent the gold standard in the diagnosis of HIT, they are technically challenging and few laboratories have the ability to perform them.

Through the analysis of a large cohort of 374 patients, we observed that IgG-anti-PF4/heparin antibodies were frequently detected in patients receiving UFH, as well as those receiving LMWH or fondaparinux. Furthermore, seroconversion of the IgG-class anti-PF4/heparin Ab was an independent risk for symptomatic DVT in these patients. However, in the sub-analysis seroconversion of the IgG-class anti-PF4/heparin Ab was not an independent risk for symptomatic DVT in patients receiving LMWHs, fondaparinux or oral anti-coagulants. These observations suggest that seroconversion of the IgG-class anti-PF4/heparin Ab could contribute to the thromboembolic complications in patients receiving UFH, and not in those receiving LMWEs or fondaparinux.

The prevalence of HIT varies between agents and its range is $1-5 \%$ for $\mathrm{UFH}$ and $0-0.8 \%$ for $\mathrm{LMWH}$ [18]. Warkentin et al. reported the seroconversion incidence

\section{Table 6 Comparison of symptomatic DVT incidence between IgG-class anti-PF4/heparin Ab seroconverted and non-seroconverted patients}

\begin{tabular}{|c|c|c|c|c|}
\hline \multirow[b]{2}{*}{ Drug } & \multicolumn{2}{|c|}{$\frac{\text { Incidence of symptomatic }}{\underline{\text { DVT (\%) }}}$} & \multirow[b]{2}{*}{$\begin{array}{l}\text { Odds ratio } \\
(95 \% \mathrm{Cl})\end{array}$} & \multirow[b]{2}{*}{$\begin{array}{c}p \\
\text { value }\end{array}$} \\
\hline & seroconverted & $\begin{array}{c}\text { non- } \\
\text { seroconverted }\end{array}$ & & \\
\hline UFH & $11 / 34(32.4 \%)$ & $5 / 70(7.1 \%)$ & $\begin{array}{l}6.217(1.951- \\
19.816)\end{array}$ & 0.001 \\
\hline LMWH & 3/9(33.3\%) & 11/86(12.8\%) & $\begin{array}{l}3.409(0.743- \\
15.642)\end{array}$ & 0.125 \\
\hline Fondaparinux & $3 / 12(25.0 \%)$ & $5 / 69(7.2 \%)$ & $\begin{array}{l}4.267(0.868- \\
20.972)\end{array}$ & 0.092 \\
\hline Others & 3/19(15.8\%) & 15/75(20.0\%) & $\begin{array}{l}0.750(0.193- \\
2.913)\end{array}$ & 0.481 \\
\hline
\end{tabular}

Abbreviations: DVT; deep vein thrombosis, UFH; unfractionated heparin, $\mathrm{LMWH}$; low-molecular weight heparin, $95 \% \mathrm{Cl}$; confidence interval. of anti-PF4/heparin Ab (fondaparinux 1.4\% vs. enoxaparin $1.3 \%$ ) and the incidence of HIT (fondaparinux $0.4 \%$ vs. enoxaparin $0.4 \%$ ) in orthopedic surgery patient receiving fondaparinux and enoxoparin [9]. In our IgGspecific immune assay, the proportion that seroconverted was $32.6 \%$ in patients receiving $\mathrm{UFH}, 9.5 \%$ for LMWHs and $14.8 \%$ for fondaprinux. Although this study was limited because we did not use functional assays, these seroconversion rates of IgG-class anti-PF4/ heparin $\mathrm{Ab}$ were shown to be relatively high with these anti-thromboembolic prophylactic therapeutics.

Non-drug factors, including type of surgery, are thought to play an important role in influencing the anti-PF4/heparin immune response. Ahamad et al. reported that anti-PF4/heparin antibody formation was higher in patients who had undergone total knee arthroplasty compared with total hip arthroplasty in clinical trial comparing UFH and LMWH [19]. More recently, Warkentin et al. demonstrated that anti-PF4/heparin antibody formation was more frequently observed after total knee arthroplasty compared with total hip arthroplasty [20]. In our study, in TKA, air tourniquest was used during operation in all patients. Hemostasis or local tissue ischemia of lower extremities related to the use of air tourniquet could partly contribute to the increased frequencies of IgG-class anti-PF4/heparin antibodies in patients receiving TKA.

It has been suggested that a syndrome resembling HIT occurs less frequently with fondaparinux [21]. This hypothesis is based on the concept that the IgG class anti-PF4/heparin antibodies are generated in fewer patients receiving fondaparinux [22]. Indeed, our study indicated that the seroconversion incidence of IgG-class anti-PF4/heparin antibody was lower in patients receiving fondaparinux compared with those receiving UFH. It has been demonstrated that fondaparinux does not activate platelets in the presence of sera obtained from patients with HIT, however UFH can activate platelets in functional platelet activation assays [23]. Also, previous studies have shown that sera obtained from patients with HIT containing anti-PF4/heparin antibodies fail to react against PF4 in the presence of fondaparinux [9]. These differences may contribute to our finding that seroconversion of the anti-PF4/heparin antibodies was not an independent risk factor for symptomatic DVT in patients receiving fondaparinux. Our results suggest that IgG-class anti-PF4/heparin antibodies generated in patients receiving fondaprinux were not able to activate platelets to induce thrombotic complications.

Our study has potential limitations. We surveyed symptomatic DVT in patients undergoing TKA or THA with different antithrombotic prophylaxis therapeutics. However, we attempted to maintain consistency 
between the patients, treatments and outcomes across the groups; i.e., all patients who underwent THA or TKA receiving standardized anticoagulant regimens, and had the same duration of follow-up. All thrombotic outcomes were confirmed with objective tests. Thus, we believe that our results provide valid estimates of the risk of symptomatic venous thromboembolism in patients who receive short-duration prophylaxis after THA or TKA. Another limitation of our study includes the performance rate of venous doppler US or computed tomography. Therefore, the incidence of DVT in the present study cannot be compared to that of previous studies. We surveyed the usage of anti-coagulants and anti-platelet agents, before and after total joint arthroplasty (TKA and THA), however, the natural products with anti-thrombotic properties had not been monitored.

In summary, symptomatic DVT developed in $15.0 \%$ of patients undergoing total joint arthroplasty (TKA and THA) with various thromboprophylaxis therapeutics. However, it was determined that the independent risk factors for DVT are elder-age ( $\geqq 75$ years) and seroconversion of the IgG-class PF4/heparin antibody. The use of UFH and TKA was associated with a higher incidence of IgG-class PF4/heparin antibodies compared with the use of LMWH or fondaparinux and THA. Furthermore, seroconversion of the IgG-class PF4/heparin antibody contributed to the occurrence of DVT more frequently in patients receiving UFH compared to those receiving LMWH or fondaparinux. These findings suggest that seroconversion of IgG-class PF4/heparin antibodies can be associated with DVT even in the absence of thrombocytopenia, in a subset of patients undergoing total joint arthroplasty (TKA and THA).

\section{Conclusion}

Seroconvertion of IgG-class anti-PF4/heparin antibodies were occurred in a significant number of patients receiving total joint arthroplasty (TKA and THA) treatments and their frequencies may depend on anti-thrombotic prophylaxis agents and types of operation (TKA or THA). Furthermore, seroconvertion of IgG-class anti$\mathrm{PH} 4 /$ heparin antibodies could be an independent risk factor for symptomatic DVT in these patients.

\footnotetext{
Abbreviations

DVT: deep vein thrombosis; HIT: heparin-induced thrombocytopenia; LMWH: low molecular weight heparin; TKA: total knee arthroplasty; THA: total hip arthroplasty; PE: pulmonary embolism; UFH: unfractionated heparin; VTE: venous thromboembolism

\section{Acknowledgements}

This study was supported by a grant from National Hospital Organization (Multi-center clinical studies for evidenced-based medicine). Special thanks to Fusae Higashi (Omura, Japan) for editing this manuscript.
}

\section{Author details}

${ }^{1}$ Department of Orthopedics Surgery and Department of Rheumatology, $\mathrm{NHO}$ Nagasaki Medical Center, Japan. ${ }^{2}$ Clinical Research Center, NHO Nagasaki Medical Center, Kubara 2-1001-1, Omura 856-8652, Japan. ${ }^{3}$ Department of Orthopedics Surgery, Nagasaki University School of Medicine, Sakamoto 1-7-1, Nagasaki 852-8501, Japan.

\section{Authors' contributions}

$\Pi$, KM, YM carried out the immunoassays. KM, SM, KO YJ HS participated in the design of the study and performed the statistical analysis. SM, SS TY conceived of the study, and participated in its design and coordination and helped to draft the manuscript. All authors read and approved the final manuscript.

\section{Competing interests}

The authors declare that they have no competing interests.

Received: 14 July 2010 Accepted: 24 January 2011

Published: 24 January 2011

\section{References}

1. Anderson FA Jr, Spencer FA: Risk factors for venous thromboembolism. Circulation 2003, 107:19-16.

2. Geerts WH, Heit JA, Clagett GP, Pineo GF, Colwell CW, Anderson FA Jr, Wheeler HB: Prevention of venous thromboembolism. Chest 2001, 119:132S-175S.

3. Geerts WH, Pineo GF, Heit JA, Bergqvist D, Lassen MR, Colwell CW, Ray JG: Prevention of venous thromboembolism: the Seventh ACCP Conference on Antithrombotic and Thrombolytic Therapy. Chest 2004, 126:338S-400S.

4. Fuji T, Fujita S, Ochi T: Fondaparinux prevents venous thromboembolism after joint replacement surgery in Japanese patients. Int Orthop 2008, 32:443-51.

5. Fuji T, Ochi T, Niwa S, Fujita S: Prevention of postoperative venous thromboembolism in Japanese patients undergoing total hip or knee arthroplasty: two randomized, double-blind, placebo-controlled studies with three dosage regimens of enoxaparin. J Orthop Sci 2008, 13:442-51.

6. Martel N, Lee J, Wells PS: Risk for heparin-induced thrombocytopenia with unfractionated and low-molecular-weight heparin thromboprophylaxis: a meta-analysis. Blood 2005, 106:2710-5.

7. Aster RH: Heparin-induced thrombocytopenia and thrombosis. N Engl J Med 1995, 332:1374-6.

8. Warkentin TE, Levine MN, Hirsh J, Horsewood P, Roberts RS, Gent M, Kelton JG: Heparin-induced thrombocytopenia in patients treated with low-molecular-weight heparin or unfractionated heparin. N Engl J Med 1995, 332:1330-5.

9. Warkentin TE, Cook RJ, Marder VJ, Sheppard JA, Moore JC, Eriksson BI, Greinacher A, Kelton JG: Anti-platelet factor 4/heparin antibodies in orthopedic surgery patients receiving antithrombotic prophylaxis with fondaparinux or enoxaparin. Blood 2005, 106:3791-6.

10. Chong BH: Heparin-induced thrombocytopenia. J Thromb Haemost 2003, 1:1471-8.

11. Greinacher A, Juhl D, Strobel U, Wessel A, Lubenow N, Selleng K, Eichler P, Warkentin TE: Heparin-induced thrombocytopenia: a prospective study on the incidence, platelet-activating capacity and clinical significance of antiplatelet factor 4/heparin antibodies of the $\lg G$, $\lg M$, and $\lg A$ classes. J Thromb Haemost 2007, 5:1666-73.

12. Juhl D, Eichler P, Lubenow N, Strobel U, Wessel A, Greinacher A: Incidence and clinical significance of anti-PF4/heparin antibodies of the $\lg G, \lg M$, and IgA class in 755 consecutive patient samples referred for diagnostic testing for heparin-induced thrombocytopenia. Eur J Haematol 2006, 76:420-6.

13. Pouplard C, Leroux D, Regina S, Rollin J, Gruel Y: Effectiveness of a new immunoassay for the diagnosis of heparin-induced thrombocytopenia and improved specificity when detecting IgG antibodies. Thromb Haemost 2010, 103:145-50.

14. Warkentin TE, Chong BH, Greinacher A: Heparin-induced thrombocytopenia: towards consensus. Thromb Haemost 1998, 79:1-7.

15. Walenga JM, Jeske WP, Prechel MM, Bacher P, Bakhos M: Decreased prevalence of heparin-induced thrombocytopenia with low-molecularweight heparin and related drugs. Semin Thromb Hemost 2004, 30:69-80. 
16. Newman PM, Chong BH: Heparin-induced thrombocytopenia: new evidence for the dynamic binding of purified anti-PF4-heparin antibodies to platelets and the resultant platelet activation. Blood 2000 96:182-7.

17. Francis JL: A critical evaluation of assays for detecting antibodies to the heparin-PF4 complex. Semin Thromb Hemost 2004, 30:359-68.

18. Warkentin $T E$, Greinacher A: Heparin-induced thrombocytopenia: recognition, treatment, and prevention: the Seventh ACCP Conference on Antithrombotic and Thrombolytic Therapy. Chest 2004, 126:311S-337S.

19. Ahmad S, Haas S, Hoppensteadt DA, Lietz H, Reid U, Bender N, Messmore HL, Misselwitz F, Bacher P, Gaikwad BS, Jeske WP, Walenga JM, Fareed J: Differential effects of clivarin and heparin in patients undergoing hip and knee surgery for the generation of anti-heparinplatelet factor 4 antibodies. Thromb Res 2002, 108:49-55.

20. Warkentin TE, Cook RJ, Marder VJ, Greinacher A: Anti-PF4/heparin antibody formation postorthopedic surgery thromboprophylaxis: the role of nondrug risk factors and evidence for a stoichiometry-based model of immunization. J Thromb Haemost 2010, 8:504-12.

21. Warkentin TE, Maurer BT, Aster RH: Heparin-induced thrombocytopenia associated with fondaparinux. N Engl J Med 2007, 356:2653-5.

22. Weitz J: New anticoagulants for treatment of venous thromboembolism. Circulation 2004, 110:119-26.

23. Savi P, Chong BH, Greinacher A, Gruel Y, Kelton JG, Warkentin TE, Eichler P, Meuleman D, Petitou M, Herault JP, Cariou R, Herbert JM: Effect of fondaparinux on platelet activation in the presence of heparindependent antibodies: a blinded comparative multicenter study with unfractionated heparin. Blood 2005, 105:139-44.

\section{Pre-publication history}

The pre-publication history for this paper can be accessed here: http://www.biomedcentral.com/1471-2474/12/22/prepub

doi:10.1186/1471-2474-12-22

Cite this article as: Motokawa et al:: IgG-class anti-PF4/heparin antibodies and symptomatic DVT in orthopedic surgery patients receiving different anti-thromboembolic prophylaxis therapeutics. BMC Musculoskeletal Disorders 2011 12:22.

\section{Submit your next manuscript to BioMed Central and take full advantage of:}

- Convenient online submission

- Thorough peer review

- No space constraints or color figure charges

- Immediate publication on acceptance

- Inclusion in PubMed, CAS, Scopus and Google Scholar

- Research which is freely available for redistribution

Submit your manuscript at www.biomedcentral.com/submit 